\title{
TRATAMENTO DE ESGOTO POR MEIO DE ZONA DE RAÍZES EM COMUNIDADE RURAL
}

\author{
Wastewater treatment by root zone in county community
}

\section{João Luiz Villas Boas Lemes ${ }^{a}$, Waldir Nagel Schirmer ${ }^{\mathrm{b}}$, Marcos Vinicius Winckler Caldeira ${ }^{\mathrm{c}}$, Tamara Van Kaick ${ }^{\mathrm{d}}$, Osnei Abel ${ }^{\mathrm{e}}$, Rozenilda Romaniw Bárbara ${ }^{\mathrm{f}}$}

${ }^{a}$ Engenheiro Ambiental. São José dos Pinhais, PR - Brasil, e-mail: engenheirovillasboas@yahoo.com.br

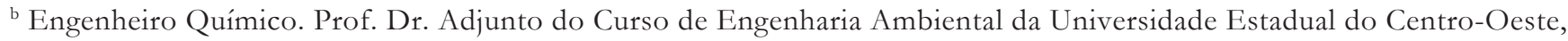
Campus Irati. Irati, PR - Brasil, e-mail:wanasch@yahoo.com.br

${ }^{\mathrm{c}}$ Engenheiro florestal. Prof. Dr. Coordenador do Curso de Engenharia Florestal da Universidade Federal do Espírito Santo. Alegre, ES - Brasil, e-mail: caldeiramv@yahoo.com.br

d Bióloga, Dra. em Tecnologia Ambiental. ECODAMATA Consultoria e Projetos Ambientais Ltda./ UFPR. Curitiba, PR - Brasil, e-mail:ecodamata@terra.com.br

e Graduado em Administração. Secretaria de Meio Ambiente da Prefeitura Municipal de Irati. Irati, PR - Brasil, e-mail: osneiabel@yahoo.com.br

${ }^{\text {f }}$ Engenheira Agrônoma. Secretaria de Planejamento da Prefeitura Municipal de Irati (SEPLAN). Irati, PR - Brasil, e-mail: rozenilda@creapr.org.br

\begin{abstract}
Resumo
A falta de tratamento de esgoto é um dos maiores problemas ambientais da população brasileira, principalmente nas comunidades rurais de baixa renda. Nesse sentido, a busca por tecnologias alternativas e de baixo custo para o tratamento desses efluentes torna-se imprescindível. Uma tecnologia alternativa aos métodos convencionais e que tem se mostrado bastante eficaz é o tratamento de esgoto por zona de raízes. Esse sistema baseia-se em princípios físicos (filtração) e biológicos, em que parte do filtro é constituída de plantas, sendo colocado à jusante de um tratamento primário (fossa séptica). Essas plantas devem ter raízes com aerênquimas bem desenvolvidos, como o copo-de-leite, que foi utilizada na ETE (Estação de Tratamento de Efluentes) proposta nesse trabalho. O mesmo teve como objetivo implantar uma estação por zona de raízes numa comunidade rural do município de Irati/PR. A ETE aqui proposta tem volume de $6 \mathrm{~m}^{3}$, foi impermeabilizada com lona plástica e é composta por um filtro físico contendo brita e areia de granulometria pré-definida. Verificou-se que a maior parte dos custos dessa ETE (totalizado em $R$ \$ 844,50) deveu-se às canalizações, uma vez que ela atendeu a duas residências. Esse valor, entretanto, situa-se na faixa de valores especificada em literatura (entre 500 e 1200 reais) e pode ficar ainda mais barato caso se preveja uma otimização no arranjo dos canos. Atualmente, a ETE está servindo ainda para trabalhos de educação ambiental nas escolas da região, além de conscientizar a comunidade local acerca da importância do tratamento de seu esgoto.
\end{abstract}

Palavras-chave: Educação ambiental; Saneamento básico; Tecnologia apropriada. 


\begin{abstract}
The lack of an appropriate wastewater treatment is one of the higher environmental problems of the Brazilian population, chiefly in those communities with a low income. Thus, the search for alternative technologies (and with a low cost) for the treatment of the wastewater become essential. An alternative technology to conventional methods is the root zone wastewater treatment plant (WWTP), which has shown quite efficient. This system focus on physical (filtration) and biological principles, in which part of the filter is made of plants, placed after the prime treatment (septic tank). These plants must have well developed aerenchyma, like calla lily, which has been used in the ETE (Effluents Treatment Station) proposed in this work. The present work had as objective to establish a root zone wastewater treatment plant in a county community, municipality of Irati, PR. The WWTP proposed has $6 \mathrm{~m}^{3}$, waterproofed with a black blanket and composed by gravel and sand with a known size. It was observed that most of the project costs ( $R \$ 844.50)$ owed to canalization, once the WWTP attended two residences. However, this price is in the range of the values found in the literature (between $R \$ 500$ and $R \$ 1,200$ ). This project is also been utilized to environmental education works in schools and also to aware the local community about the importance of the sewerage treatment.
\end{abstract}

Keywords: Appropriated technology; Basic sanitation; Environmental education.

\title{
INTRODUÇÃO
}

A falta de tratamento dos esgotos sanitários é considerado um dos maiores problemas ambientais da população brasileira. Segundo o IBGE (2007), no Brasil, 47,2\% da população não possui rede coletora de esgoto nem ao menos fossa séptica. Isso significa que quase 100 milhões de habitantes não dispõem desses serviços; o problema é ainda mais grave nas comunidades rurais e de baixa renda. O Estado do Paraná não está muito diferente da situação atual brasileira. Segundo o IPARDES (2007), 83,6\% dos domicílios são atendidos pelos serviços de abastecimento de água potável, mas apenas 37,6\% são atendidos por rede coletora de esgoto e o percentual é ainda mais reduzido quando se trata de tratamento adequado do esgoto coletado.

A qualidade e o acesso aos serviços de saneamento estão diretamente relacionados à saúde publica. Água encanada e tratada é considerada um grande benefício para as comunidades, mas se esse serviço não vier acompanhado de um sistema de tratamento de esgoto adequado poderá, em certos casos, não acabar com os problemas de saúde relacionados à veiculação hídrica, tal como verminoses, hepatite e diarréia. A Fundação Nacional de Saúde destaca que, a cada $\mathrm{R} \$ 1,00$ investido no setor de saneamento, cerca de R \$4,00 é economizado com a saúde (FUNASA, 1994).

Devido à situação sócio-econômica brasileira, são inevitáveis os investimentos no desenvolvimento de tecnologias alternativas, de baixo custo e de alta eficiência para o tratamento das águas residuárias. O tratamento de esgoto utilizando plantas está se revelando uma alternativa eficiente e de baixo custo quando comparadas aos sistemas convencionais. Segundo Brix (1994), esses sistemas podem ser implementados no mesmo local onde o efluente é produzido, podem ser operados por mão de obra não especializada, possuem baixo custo energético e são menos susceptíveis às variações nas taxas de aplicação de esgoto.

De acordo com o CETEC (1985), uma solução apropriada para localidades do meio rural é o sistema de Tratamento de Esgoto Sanitário por Zona de Raízes. Esse sistema tem base em solos filtrantes e é uma tecnologia auto-sustentável, pode ser utilizado de forma a atender pequenas comunidades, escolas e residências unifamiliares, ocupa pequeno espaço na área externa da residência e ainda pode ser integrado de forma não agressiva ao ambiente. Outra vantagem desse sistema é que o 
tratamento do esgoto passa por duas etapas: o tratamento primário (fossa séptica) e o secundário (ETE por meio de zona de raízes), podendo o efluente resultante do tratamento ser devolvido, apresentando uma redução significativa de matéria orgânica e sólidos sedimentáveis, evitando, assim, a contaminação do corpo d'água ao qual o efluente será lançado. Outro aspecto positivo do sistema é ausência da produção de lodo, o que muitas vezes provoca mau cheiro (secagem lenta) com alto custo (secagem mecânica); na zona de raízes, o mau cheiro é evitado porque as próprias raízes funcionam como um filtro, eliminando-o (VAN KAICK, 2002).

Este trabalho descreve a primeira etapa da implantação de solução tecnológica apropriada para o tratamento de esgoto em duas residências rurais no distrito de Gonçalves Júnior, município de Irati (PR), por meio do sistema de zona de raízes. A conversão das propriedades de agricultores familiares para a produção agroecológica e de produtos orgânicos exige que os aspectos de saneamento ambiental sejam atendidos nestas propriedades. Dessa forma, a introdução de tecnologias apropriadas para o tratamento de esgoto nestas propriedades permite que elas possam se adequar às exigências para a certificação de propriedades de produção orgânica. Além disso, a implantação visa reduzir (ou mesmo eliminar) problemas decorrentes de odor e descarte inapropriado de resíduos, problemas contestados, já há algum tempo, pela comunidade. Esse fator, inclusive, foi determinante para o apoio de todas as pessoas envolvidas no projeto.

\section{Funcionamento da ETE por meio de zona de raízes}

A estação de tratamento de esgoto por zona de raízes é um sistema físico-biológico, com parte do filtro constituído de plantas. O esgoto bruto é lançado através de uma rede de tubulações perfuradas que é instalada logo abaixo da zona de raízes, área plantada. Esta área é dimensionada de acordo com a demanda de esgoto já pré-determinada (VAN KAICK, 2002).

De acordo com Sipinski e Van Kaick (2000), a área para o tratamento de esgoto de uma estação experimental em Antonina (PR) foi de $1 \mathrm{~m}^{2}$ para cada habitante, com profundidade de $1 \mathrm{~m}$. Segundo Ambros, Ehrhardt e Kerschbaumer (1998, apud VAN KAICK 2002), a média anual de evaporação de água através das plantas pode chegar a 1.000 litros, o qual corresponde a $25 \%$ da evaporação da água que entra na estação de tratamento. Já em climas tropicais, como é o caso do Brasil, a probabilidade de evaporação pode ser ainda maior, devido à insolação mais contínua ao longo do ano. Com isso, em experimentos brasileiros, pode haver uma redução da área da ETE por zona de raízes.

Nesse tipo de estação, o efluente primeiro passa por um tratamento primário, geralmente por uma fossa séptica, onde são removidos os sólidos sedimentáveis; logo após, o efluente é encaminhado através de uma rede de tubulações perfuradas para ETE por zona de raízes, mais ou menos a uns $10 \mathrm{~cm}$ abaixo da superfície do filtro, onde é iniciado o tratamento secundário. Para Van Kaick (2002), as plantas que constituem a zona de raízes devem ser plantadas sobre um filtro físico estruturado por uma camada de brita $\mathrm{n}^{\circ} 2$, de $50 \mathrm{~cm}$ de profundidade, e sobre a rede de distribuição do efluente bruto. Logo abaixo da camada de brita encontra-se outra camada do filtro, que é constituída de areia (com granulometria de média para grossa) de $40 \mathrm{~cm}$ de profundidade. No fundo do filtro ficam as tubulações de coleta do efluente tratado, que são conduzidos para fora da estação através da diferença de nível. Para evitar a contaminação do solo ou até mesmo do lençol freático e infiltrações indesejáveis no sistema, a ETE deve ser impermeabilizada com lona plástica resistente, ou por uma estrutura de concreto armado.

Segundo Valentin (1999), devido à topografia do terreno, em alguns casos, existe a necessidade do uso de bombas elétricas para conduzir o efluente até a ETE, isso ocorre quando as alternativas de condução não ofereçam o caimento mínimo necessário, ou quando a fossa séptica está abaixo do nível da ETE. Quando não houver a necessidade do uso de bombas, o sistema todo funciona sem gasto de energia e utiliza a gravidade como força motriz para conduzir o efluente, com isso o sistema torna-se de baixo custo e com pouquíssima manutenção. A Figura 1 mostra o esquema simplificado de uma ETE por zona de raízes. 


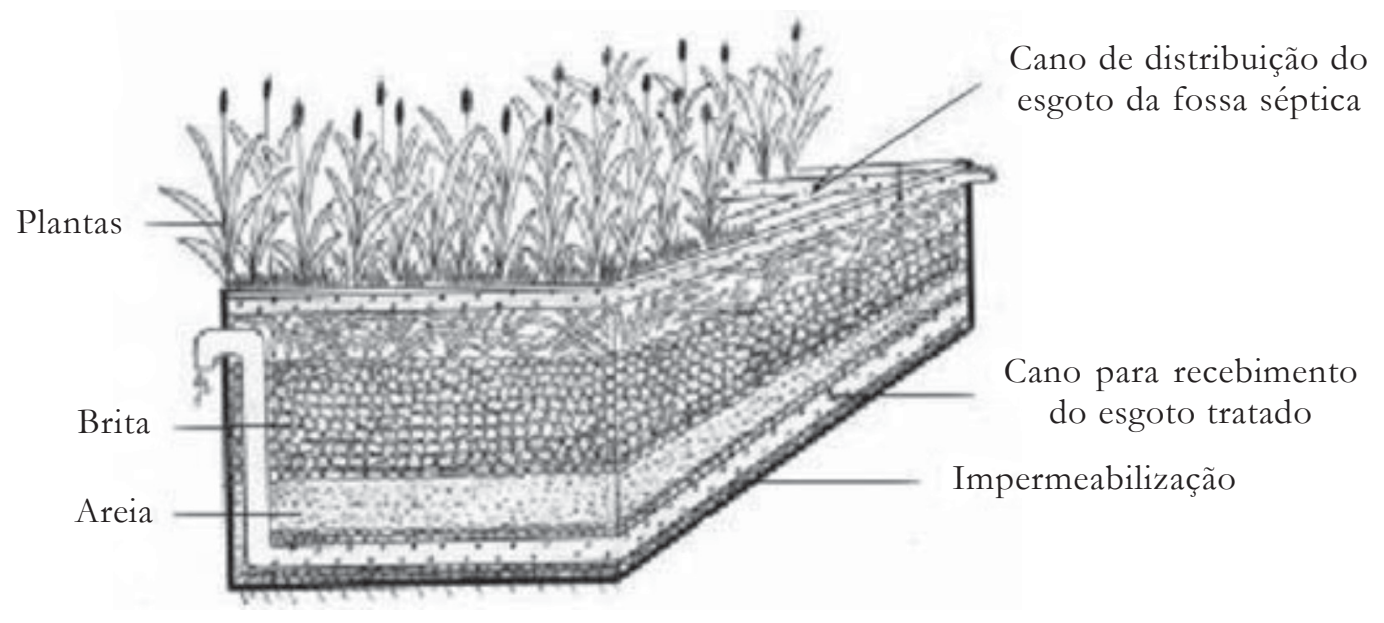

FIGURA 1 - Esquema de uma ETE por meio de zona de raízes Figure 1 - WWTP by roots zone

Fonte: Adaptado de VAN KAICK, 2002.

Para Valentin (1999), o tratamento das águas residuárias na ETE por zona de raízes é o resultado da união entre os processos físicos, químicos e biológicos que ocorrem por causa do filtro físico, das comunidades bacterianas e macrófitas. As bactérias ${ }^{1}$ são fundamentais para o tratamento do efluente, uma vez que são responsáveis pela degradação da matéria orgânica presente no efluente por meio de processos anaeróbios, anóxicos e aeróbios. As condições aeróbias e anóxicas só acontecem devido ao fornecimento de oxigênio pelas raízes das macrófitas.

O oxigênio captado pelas folhas das macrófitas é levado através do caule até as raízes, não apenas para suprir a demanda respiratória dos tecidos das raízes, mas também para oxigenar sua rizosfera. A saída do oxigênio das raízes para o filtro cria condições de oxidação no meio, possibilitando, assim, a decomposição da matéria orgânica (BRIX, 1994). O transporte do oxigênio atmosférico no interior das plantas aquáticas ocorre devido à presença de grandes espaços internos de ar chamados aerênquimas, que podem chegar a ocupar até $60 \%$ do volume dos tecidos das macrófitas. Com isso, o bom funcionamento da ETE por zona de raízes depende de plantas com uma rede muito bem desenvolvida de aerênquimas (BAHLO; WACH, 1996).

A espécie mais comumente utilizada na zona de raízes, principalmente por sua fácil adaptação, é a Zantedeschia aethiopica, popularmente conhecida como copo-de-leite. O copo-de-leite é uma macrófita pertencente à família da Araceae (angiosperma e monocotiledônea). Sua família botânica é composta por 107 gêneros e cerca de 3.000 espécies, a maioria característica de solos ricos em matéria orgânica e brejos, ou seja, ecossistemas úmidos. Essas plantas podem chegar a $1 \mathrm{~m}$ de altura e crescem na presença de sol intenso. Suas flores são firmes e duráveis e seus frutos são do tipo baga. Elas são frequentemente usadas como plantas domésticas e como decoração de jardins. O copo-de-leite também é conhecido como lírio-do-nilo, cala-branca, jarra ou jarro (JOLY, 1979).

\footnotetext{
${ }^{1}$ Segundo VAN KAICK (2002), as bactérias que removem a matéria orgânica na ETE por zona de raízes podem ser aeróbias (só se desenvolvem na presença de oxigênio), anaeróbias estritas (se desenvolvem na ausência de oxigênio) ou ainda anaeróbias facultativas (podem crescer tanto na ausência quanto na presença de oxigênio).
} 


\section{MATERIAIS E MÉTODOS}

\section{Área de estudo}

A ETE piloto por zona de raízes foi implantada para atender à demanda de duas propriedades (num total de 5 pessoas) localizadas no Distrito de Gonçalves Júnior, município de Irati, PR, a 18 km do centro da cidade.

No distrito residem, atualmente, cerca de 235 pessoas, das quais 219 (o que compreende 93,2\% de seus habitantes) possui atendimento de água potável, mas nenhum tipo de rede coletora de esgoto (WAGNER, 2007). No distrito existem ainda duas escolas (a Escola Municipal dos Colonizadores e a Escola Estadual Gonçalves Júnior, ambas ocupando o mesmo prédio), um posto de saúde e seis igrejas, sendo que a economia predominante na região é a agricultura de fumo.

\section{Metodologia usada para a implantação da ETE}

Para a construção da ETE piloto foram utilizados parâmetros estruturais encontrados na literatura para diferentes ETEs já construídas e em operação. A construção priorizou a utilização de materiais de baixo custo e plantas nativas ou facilmente adaptáveis à região (caso do copo-de-leite). Todo o material utilizado na construção da ETE foi doado pela Prefeitura de Irati, bem como a construção, que ainda contou com a ajuda dos moradores das residências-piloto. A construção foi ainda acompanhada pela empresa Eco da Mata, de Piraquara (PR), especializada na construção de ETE por zonas de raízes. A Figura 2 apresenta um esquema da localização das fossas sépticas e da ETE em relação às residências.

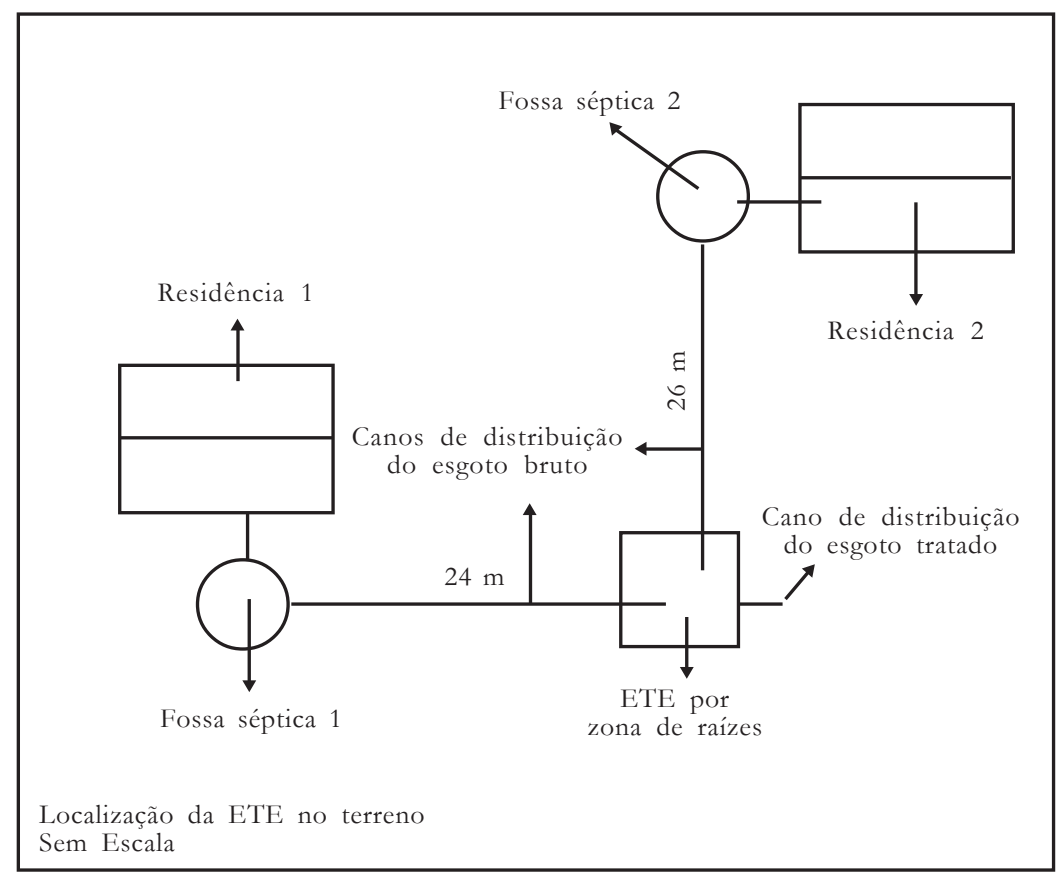

FIGURA 2 - Localização da ETE em relação as duas residências Figure 2 - WWTP location in the neighboring of two residences 


\section{Construção do tanque e impermeabilização do solo da ETE}

As fossas sépticas responsáveis pelo tratamento primário dos efluentes já estavam devidamente construídas nas residências utilizadas para implantação do projeto piloto. Nesse caso, foram acrescentadas apenas as canalizações necessárias para que o efluente pudesse ser conduzido para a ETE por zona de raízes.

Devido à topografia do terreno e o caimento necessário para que ocorra a percolação do efluente, a ETE foi implantada logo abaixo da superfície do solo. O solo foi escavado com uma dimensão de 2,3’2,5 m (área total de 6,00 $\mathrm{m}^{2}$ ) e com profundidade de $1 \mathrm{~m}$ (Figura 3). Afim de prevenir qualquer tipo de contaminação (do solo ou do lençol freático) a base da ETE (piso e laterais) foi impermeabilizada com uma tripla camada de lona plástica preta de $0,2 \mathrm{~mm}$.
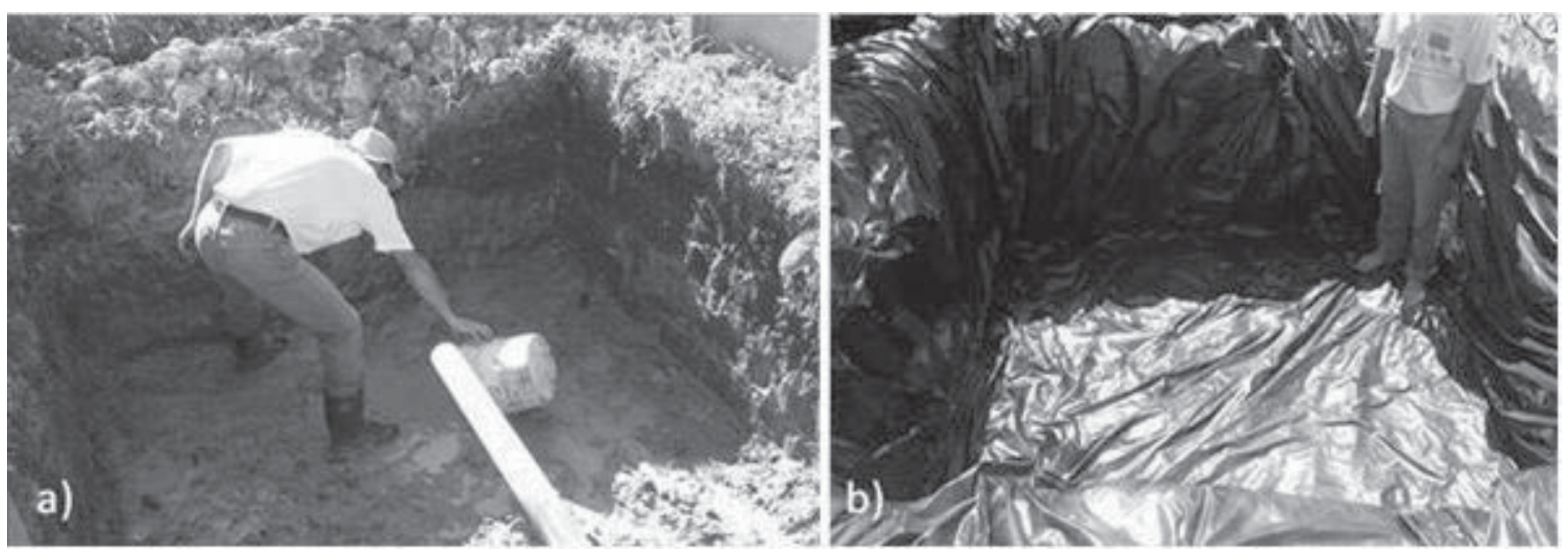

FIGURA 3 - a) Escavação no Solo

b) Impermeabilização da ETE piloto

Figure 3 - a) Excavation in the ground

b) Pilot-scale WWTP waterproofing

\section{Canalização de distribuição do esgoto bruto, captação do esgoto da ETE e composição do filtro físico}

Para a implantação da ETE piloto foram adquiridas 11 barras de PVC, de $6 \mathrm{~m}$ cada. Ao todo, foram utilizados $50 \mathrm{~m}$ de cano para a rede de distribuição do efluente para ETE $(24 \mathrm{~m}$ da fossa 1 até a ETE e $26 \mathrm{~m}$ da fossa 2 até a ETE) e $10 \mathrm{~m}$ para a rede de captação do efluente tratado (da ETE até a vala que encaminha o efluente ao rio). Todos os canos utilizados possuem $75 \mathrm{~mm}$ de diâmetro, isso para que seja atingida a velocidade adequada ao escoamento do esgoto. As perfurações necessárias para a distribuição do esgoto (proveniente da fossa) e coleta (do esgoto tratado na ETE) foram feitos com broca de $08 \mathrm{~mm}$, com intervalo de $20 \mathrm{~cm}$ entre os furos. A rede de canos que capta o esgoto tratado (no fundo do tanque) forma um quadro de 1,6'1,6 $\mathrm{m}$ com dois respiros localizados em lados opostos (Figura 4). De acordo com Van Kaick (2002), os respiros, que nada mais são do que meios de acesso às canalizações do efluente tratado, devem ser tampados para evitar a proliferação de ovos de pernilongos, a entrada de luz e, consequentemente, a ocorrência de proliferação de algas e ainda para evitar que se jogue lixo dentro do encanamento. prejudicando o funcionamento da ETE. Toda canalização do fundo do tanque foi protegida com uma camada de brita $n^{\circ} 02$, para que não ocorresse o entupimento dos furos pela areia. 

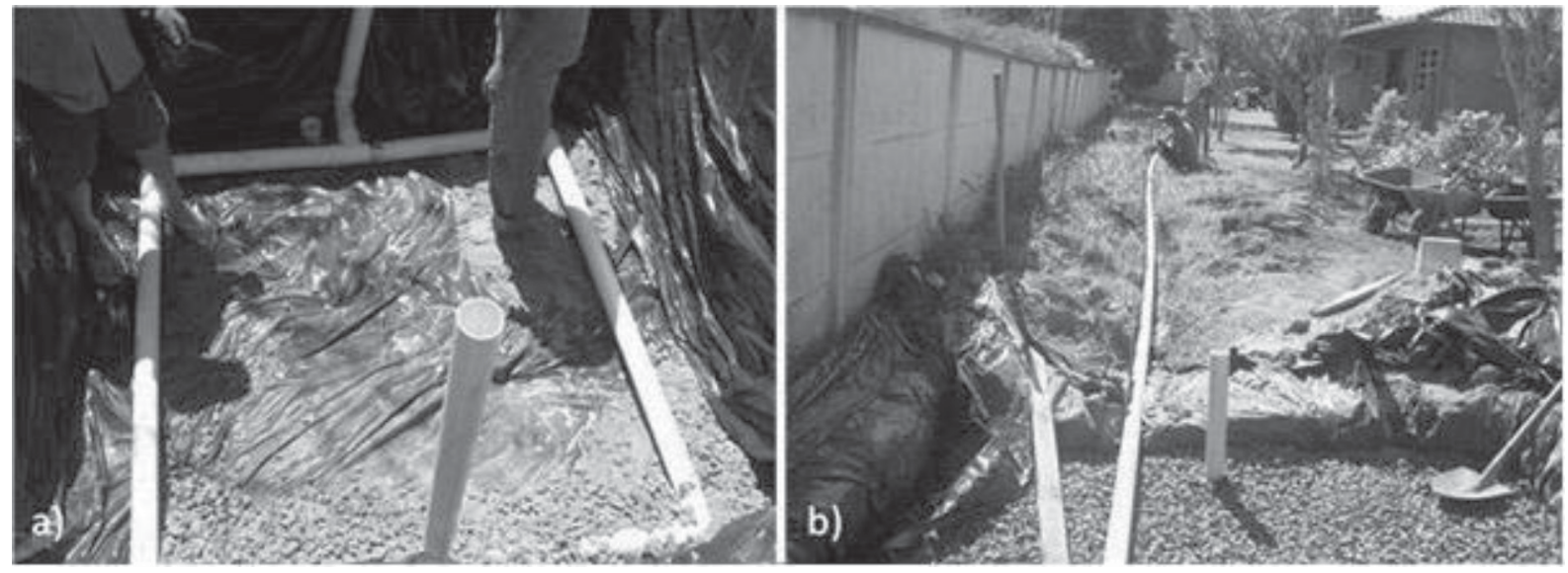

FIGURA 4 - a) Canos de coleta do esgoto tratado

b) Canos de distribuição do esgoto bruto

Figure 4 - a) Collect pipes from the treated sewage

b) Supplier pipes of raw sewage

O filtro físico da ETE por zona de raízes foi composto, ainda, por uma camada de $40 \mathrm{~cm}$ de areia média seguida de nova camada de brita $($ de $60 \mathrm{~cm}$ ) (Figura 5). Essa segunda camada de brita cobre a canalização de distribuição do esgoto (proveniente da fossa) em $10 \mathrm{~cm}$. A diferença de nível entre os canos de chegada da fossa e saída da ETE também é de $10 \mathrm{~cm}$.

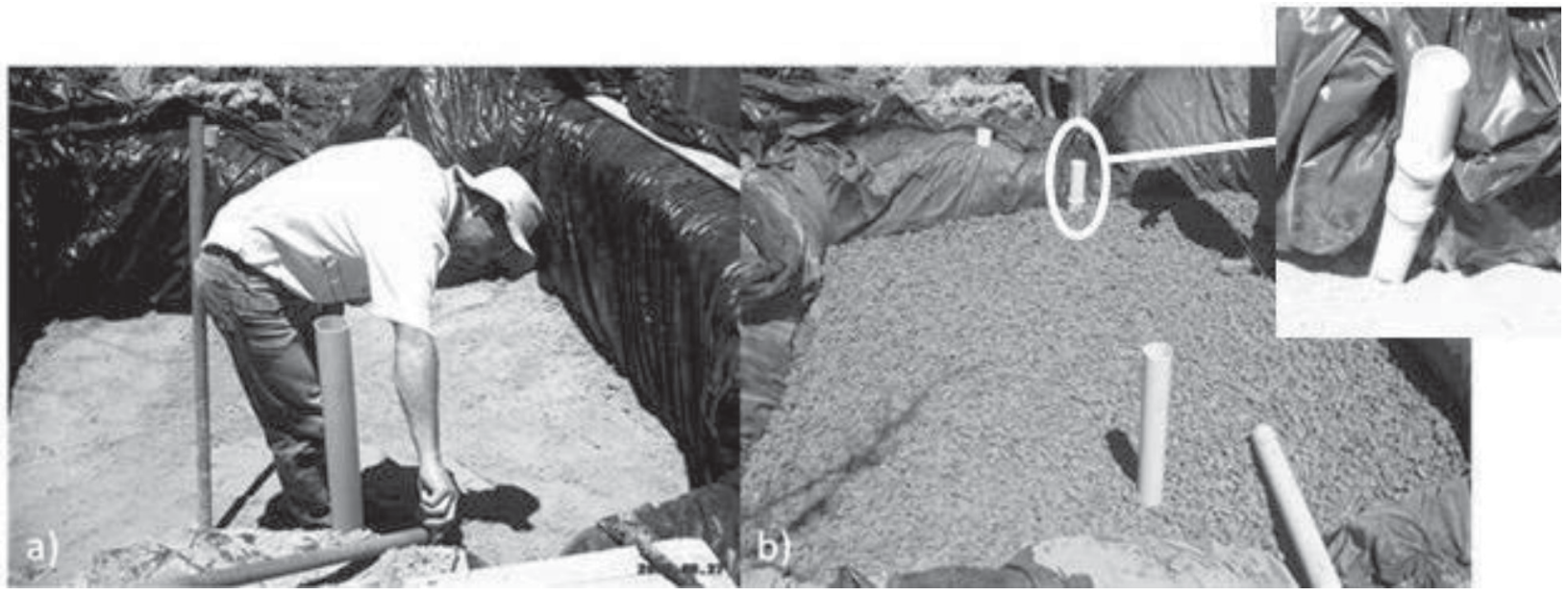

FIGURA 5 - Composição do filtro com areia média e brita $n^{\circ} 02$. No detalhe, o ponto de saída do esgoto tratado

Figure 5 - Filter composed by medium sand and gravel $n^{\circ}$ 02. In detail, the outlet of treated sewage

\section{Composição da zona de raízes}

Para compor a zona de raízes foi utilizada a planta Zantedeschia aethiopica (copo-de leite) (Figura 6). Essa planta foi escolhida por apresentar todas as caracteríticas necessárias (descritas na Introdução) para o tratamento proposto, além de ter demonstrado bons resultados (encontrados em literatura específica) no tratamento de efluentes domésticos. As plantas foram coletadas na própria residência de implantação da ETE. Foram plantadas ao todo 16 mudas de copo-de-leite na própria brita. 


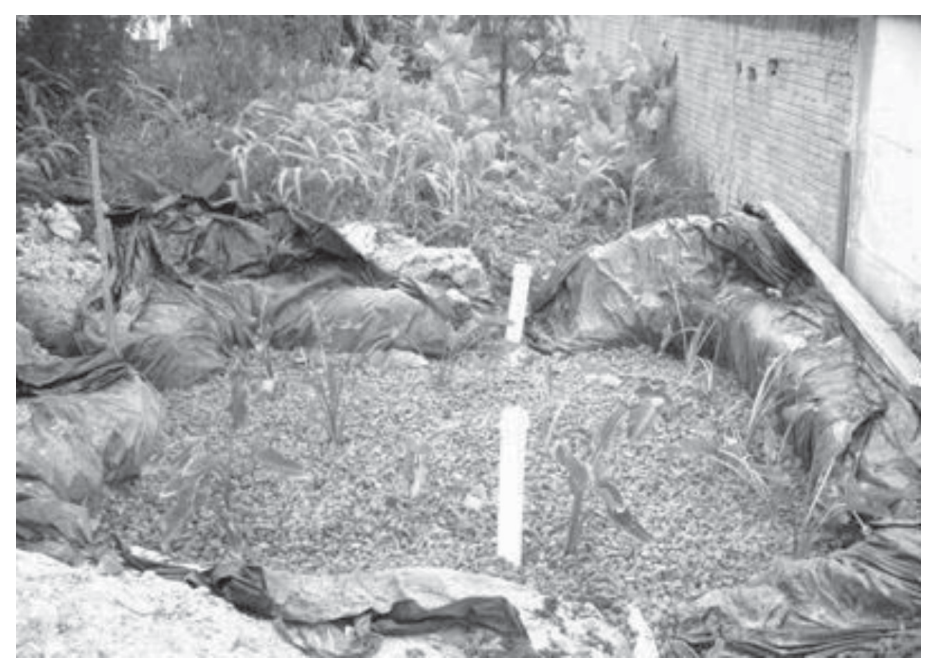

FIGURA 6 - Copos-de-leite plantados na ETE piloto

Figure 6 - Calla lily planted on the pilot-scale WWTP

\section{RESULTADOS E DISCUSSÃO}

\section{Educação ambiental como resultado da implantação da ETE piloto}

A implantação da ETE está servindo como exemplo de projeto social alternativo; além disso, está sendo utilizada para esclarecer as dúvidas sobre o saneamento básico da região e promover o conceito de desenvolvimento sustentável para toda comunidade. As escolas estão aproveitando a ETE para as aulas de Ciências, aplicando na prática os conhecimentos adquiridos em sala de aula. A ETE também está servindo para a conscientização do problema do esgoto e da importância do seu tratamento, uma vez que as pessoas já estão verificando, na prática, os benefícios desse tratamento.

\section{Relação dos custos de implantação da ETE piloto}

O sistema de tratamento de esgoto por zona de raízes é uma tecnologia de baixo custo de implantação, operação e manutenção quando comparada a outras tecnologias de tratamento convencional. A Tabela 1 apresenta o custo por habitante de alguns sistemas convencionais de tratamento comparados ao custo do tratamento por zona de raízes, similar ao implantado no Distrito de Gonçalves Júnior.

TABELA 1 - Eficiência na remoção de matéria orgânica e custo do tratamento (em US\$) por habitante de alguns sistemas de tratamento de esgoto

Table 1 - Organic removal efficiency and treatment cost (in US\$) per resident in some wastewater treatment systems

\begin{tabular}{lcc}
\hline \multicolumn{1}{c}{$\begin{array}{c}\text { Sistema de } \\
\text { tratamento }\end{array}$} & $\begin{array}{c}\text { Eficiência na remoção de Matéria } \\
\text { Orgânica - analisado como DBO (\%) }\end{array}$ & Custo (US\$ /hab.) \\
\hline Tratamento preliminar & $0-5$ & $2-8$ \\
Tratamento primário & $35-40$ & $20-30$ \\
Lagoas sem aeração & $80-90$ & $10-30$ \\
Disposição no solo & $85-95$ & $5-20$ \\
Sistemas anaeróbios & $60-90$ & $10-30$ \\
Lagoas com aeração & $80-93$ & $40-120$ \\
Filtros biológicos & $80-93$ & $40-120$ \\
Lodos ativados & $85-98$ & $40-115$ \\
\hline Zona de raízes & $77-98$ & \\
\hline
\end{tabular}

Fonte: BARROS et al. (1995, apud VAN KAICK, 2002). 
Como pode ser observado na Tabela 1, o sistema de tratamento por zona de raízes consegue uma eficiência (77-98) que pode ser comparada aos sistemas de tratamento mais caros. Segundo Van Kaick (2002), para implantar uma ETE por zona de raízes, os custos podem variar entre $\mathrm{R} \$ 500,00$ a $\mathrm{R} \$ 1.200,00$ por unidade, dependendo do material utilizado na impermeabilização do solo. A implantação da ETE piloto descrita neste trabalho levou cerca de 3 dias para ser totalmente realizada e a relação de todo material de construção utilizado na implantação e seus respectivos custos estão relacionados na Tabela 2.

TABELA 2 - Relação dos materiais e seus custos utilizados para construir a ETE piloto

Table 2 - Materials and their cost used to build the pilot-scale WWTP

\begin{tabular}{lcr}
\hline Material Utilizado & Quantidade & Valor (R\$) \\
\hline Tudo de PVC $75 \mathrm{~mm}$ & $66 \mathrm{~m}$ & 407,00 \\
Joelho de $90^{\circ} 75 \mathrm{~mm}$ & 5 & 40,00 \\
Tês $75 \mathrm{~mm}$ & 3 & 24,00 \\
Redução de 100 para $75 \mathrm{~mm}$ & 1 & 8,00 \\
Tampão 75 mm & 4 & 12,00 \\
Areia média & $3 \mathrm{~m}^{3}$ & 105,00 \\
Brita no 02 & $3,5 \mathrm{~m}^{3}$ & 123,50 \\
Mão de obra específica & $2 \mathrm{dias}^{2}$ & 80,00 \\
Lona plástica preta & $105 \mathrm{~m}^{2}$ & 45,00 \\
Planta para zona de Raízes & $16 \mathrm{mudas}^{\circ}$ & Sem custo \\
\hline Total & & 844,50 \\
\hline
\end{tabular}

A Tabela 3 mostra a relação dos custos dos materiais utilizados na implantação de uma ETE por meio de zona de raízes em duas situações diferentes (uma com base de concreto armado e outra com lona plástica) também construída para atender uma demanda de 5 pessoas, similar à ETE piloto de Gonçalves Júnior.

TABELA 3 - Custos dos materiais de construção de uma ETE por zona de raízes em duas situações distintas, em Ilha Rasa (2001)

Table 3 - Costs of building materials of a WWTP by root zone in two different situations, in Ilha Rasa (2001)

\begin{tabular}{lcc}
\hline Material & ETE 1 (tempo previsto: 8 dias) & ETE 2 (tempo previsto: 4 dias) \\
\hline Cimento 8 sacos de $50 \mathrm{~kg}$ & $\mathrm{R} \$ 120,00$ & Não utiliza \\
Ferragem $50 \mathrm{~m}$ & $\mathrm{R} \$ 32,80$ & Não utiliza \\
Areia (caixa de concreto $1 \mathrm{~m}^{3}$ ) & $\mathrm{R} \$ 15,00$ & Não utiliza \\
Areia (filtro físico $6 \mathrm{~m} 3)$ & $\mathrm{R} \$ 90,00$ & $\mathrm{R} \$ 90,00$ \\
Brita $\mathrm{n}^{\circ} 0$ (caixa de concreto $2 \mathrm{~m}^{3}$ ) & $\mathrm{R} \$ 40,00$ & Não utiliza \\
Brita $\mathrm{n}^{\circ}$ 2 (filtro físico) & $\mathrm{R} \$ 132,00$ & $\mathrm{R} \$ 132,00$ \\
Conchas de ostras nativas & $\mathrm{Sem}$ custo & Sem custo \\
Plantas nativas & $\mathrm{Sem}$ Custo & Sem custo \\
Tubos de PVC $75 \mathrm{~mm} / 14 \mathrm{~m}$ & $\mathrm{R} \$ 36,20$ & $\mathrm{R} \$ 36,20$ \\
Tubos de PVC $75 \mathrm{~mm} / 9 \mathrm{~m}$ & $\mathrm{R} \$ 30,00$ & $\mathrm{R} \$ 30,00$ \\
Fossa Séptica/ 5 pessoas & $\mathrm{R} \$ 30,00$ & $\mathrm{R} \$ 30,00$ \\
Lona preta $14 \mathrm{~m}$ x $18 \mathrm{~m}$ & $\mathrm{~N}$ ão utiliza & $\mathrm{R} \$ 33,00$ \\
\hline Total & $\mathrm{R} \$ 526,00$ & $\mathrm{R} \$ 351,20$ \\
\hline
\end{tabular}

Fonte: Adaptado de Van Kaick (2002).

Rev. Acad., Ciênc. Agrár. Ambient., Curitiba, v. 6, n. 2, p. 169-179, abr./jun. 2008 
Quando comparadas as Tabelas 2 e 3, nota-se que a ETE piloto, construída no distrito, ficou relativamente onerosa. Nesse caso, a maior contribuição para esse custo está no valor das canalizações (responsáveis pela condução do efluente bruto da fossa séptica até a ETE piloto). Deve-se salientar, entretanto, que a ETE abordada nesse trabalho atende a duas residências (e não apenas uma como acontece nas ETE da Tabela 3); daí a necessidade de uma maior quantidade de canos e, portanto, recursos adicionais.

\section{CONCLUSÕES}

Além de economicamente viável, a implantação da ETE por meio de zona de raízes pôde ser empregada como uma ferramenta de apoio para propostas de educação ambiental, sendo essa utilizada para demonstrar a importância da preservação da qualidade da água que pode trazer benefícios sociais, econômicos e ambientais à localidade. A ETE também serviu para a inserção do conceito de desenvolvimento sustentável na pequena comunidade rural de Gonçalves Júnior, onde o grau de informação e escolaridade da maioria dos habitantes é baixo;

Está previsto, para iniciar em 2008, a $2^{\circ}$ etapa do projeto (etapa de monitoramento), de grande importância para a boa manutenção e otimização dos parâmetros da ETE. Todos os resultados obtidos serão apresentados à comunidade, para que seja comprovada a eficiência do tratamento de esgoto por meio de zona de raízes e, também, para que a tecnologia possa ser mais aceita pela comunidade. Serão realizadas mensalmente análises de DBO, DQO, coliformes totais e Escherichia coli;

Para futuros trabalhos, recomenda-se fazer a ETE por zona de raízes o mais próximo possível da fossa séptica, para que se reduzam significativamente os custos relativos à canalização (nesse trabalho, o material mais oneroso da implantação da ETE);

Por fim, é necessário o incentivo de pesquisas para o desenvolvimento de tecnologias alternativas para solucionar os problemas de saneamento básico para localidades do meio rural e comunidades carentes.

\section{AGRADECIMENTOS}

Os autores agradecem à Prefeitura Municipal de Irati pelo apoio financeiro, à empresa Eco da Mata pelo apoio técnico, aos moradores de Gonçalves Júnior e Escola dos Colonizadores/Gonçalves Júnior pela colaboração, principalmente na fase de implantação do projeto.

\section{REFERÊNCIAS}

AMBROS, R.; EHRHARDT, M.; KERSCHBAUMER, J. Pflanzen-Kläranlagen Selbst Gebaut. Stuttgart: Leopoldo Stocker Verlag, 1998.

BAHLO, K.; WACH, G. Naturnahe Abwasserreiningung. Staufen bei Freiburg: Ökobuch Verlag, 1996.

BARROS, R. T. V. et al. Manual de saneamento e proteção ambiental para os municípios. Belo Horizonte, MG: DESA/UFMG, 1995.

BRIX, H. Function of macrophytes in constructed wetlands. Water Science and Technology, London, v. 29, n. 4, p. 71-78, 1994. 
FUNDAÇÃO CENTRO TECNOLÓGICO DE MINAS GERAIS - CETEC. Prática de implantação de disseminação de tecnologias apropriadas ao meio rural - projeto juramento. Belo Horizonte, 1985.

FUNDAÇÃO NACIONAL DE SAÚDE - FUNASA. Manual de saneamento. Brasília: Ministério da Saúde, 1994. 255 p.

INSTITUTO BRASILEIRO DE GEOGRÁFIA E ESTATÍSTICA - IBGE. Censo 2000. Disponível em:<http://wwwl.ibge.br/ibge/estatistica/populacao/condicaodevida/indicadoresminimos/ tabela3.shtm>. Acesso em: 05 out. 2007.

INSTITUTO PARANAENSE DE DESENVOLVIMENTO ECONOAMICO E SOCIAL IPARDES. Índice de desenvolvimento humano municipal - IDH-M, 2000. Disponível em: <www.pr.gov.br/ipardes/pdf/idmh_2000.pdf> Acesso em: 6 out. 2007.

JOLY, A. B. Botânica: introdução à taxonomia vegetal. 5. ed. São Paulo: Nacional, 1979.

SIPINSKI, M. A.; VAN KAICK, T. S. Estação de tratamento de esgoto (ETE) piloto na Reserva Morro da Mina/SPVS, Antonina Paraná. Cadernos do Litoral, Curitiba, n. 3, p. 64, 2000.

VALENTIM, M. A. A. Uso de leitos cultivados no tratamento de efluentes de tanque séptico modificado. 1999. 119 f. Dissertação (Mestrado em Engenharia Agrícola) - Universidade Estadual de Campinas, Campinas, 1999.

VAN KAICK, T. S. Estação de tratamento de esgoto por meio de zona de raízes: uma proposta de tecnologia apropriada para saneamento básico no litoral do Paraná. 2002. 128 f. Dissertação (Mestrado em Tecnologia) - Universidade Tecnológica Federal do Paraná, Curitiba, 2002.

WAGNER, L. F. Disponibilidade dos recursos hídricos $\mathbf{x}$ demanda futura do município de Irati. Irati: SANEPAR, 2007. 